\title{
PROPAGAÇÃo DE Dovyalis sp. PELO PROCESSO DE MERGULhia AÉREA ${ }^{1}$
}

\author{
EDUARDO JOSÉ DE ALMEIDA², NATANAEL DE JESUS, RITA MARIA DEVÓS GANGA, ANTONIO CARLOS \\ BENASSI, ERIVALDO JOSÉ SCALOPPI JUNIOR., ANTONIO BALDO GERALDO MARTINS ${ }^{3}$
}

\begin{abstract}
RESUMO - Com objetivo de avaliar a capacidade de propagação vegetativa de Dovyalis sp. pelo método da alporquia, realizou-se o presente trabalho. Foram utilizados ramos com cerca de 50 centímetros, os quais receberam os tratamentos: 0; 1.000; $3.000 ; 5.000$ e $7.000 \mathrm{mg} / \mathrm{kg}$ de ácido indolbutírico (AIB) diluídos em lanolina, em duas épocas do ano: outono e primavera. No outono, considerou-se como subparcelas as localizações dos alporques por toda a planta, analisando-as como alporques da parte superior e inferior da copa e das faces norte e sul da planta. Na primavera, por insuficiência de ramos, apenas foram consideradas as doses com AIB. Nas épocas estudadas, o outono foi a que demonstrou maior percentagem de enraizamento e número de raízes (93,93 e 10,26 \%, respectivamente). Obteve-se que o enraizamento independe da posição do ramo na planta, para esta época. O maior comprimento de raízes foi obtido na primavera.
\end{abstract}

Termos de indexação: Dovyalis, alporquia, auxina, propagação vegetativa.

\section{Dovyalis sp PROPAGATION BY AIR-LAYERING PROCESS}

\begin{abstract}
Aiming to stud the capacity of vegetative propagation of Dovyalis sp. by layering method, this work was developed. It was used branches of $50 \mathrm{~cm}$ length, which received the following treatments: 0; 1,000;3,000; 5,000 and 7,000 $\mathrm{mg} / \mathrm{kg}$ of indolbutiric acid (IBA) diluted in lanolina, in two periods: autumn and spring. In autumn the layering was distributed in superior and inferior part of the canopy and north and south sides of the plant. In spring, due to few branches it was just considered treatments with IBA. The autumn period demonstrated the highest percentage of root formation $(93.93 \%)$ and number of roots $(10.26 \%)$, and the root formation do not depend on branch position on the plant. The highest length of root was obtained in spring.
\end{abstract}

Index terms: Dovyalis, marcottage, auxin, vegetative propagation.

\section{INTRODUÇÃO}

Apesar de o Brasil possuir uma grande quantidade de espécies frutíferas nativas, principalmente as tropicais, a introdução de espécies exóticas ou de suas seleções melhoradas tem um grande interesse, no sentido de possibilitar a diversificação com seu cultivo (Donadio, 1991).

Segundo comunicação pessoal de Godas (2003), em 1991, o setor de frutas da Ceagesp movimentou 1.467.101 t, sendo que deste total, $22.000 \mathrm{t}$ foram de frutas exóticas, correspondendo a 1,5\% do setor. Em 2001, o movimento total de frutas naquela instituição foi de 1.476.245 t, e as frutas exóticas passaram a representar 2,98 \% do setor, praticamente dobrando a comercialização com $44.000 \mathrm{t}$ de frutas comercializadas.

Dovyalis caffra (Hook. f. e Harv.) Warb., conhecida comumente nos Estados Unidos da América como "Key apple", ou "umkokolo", é originária da África do Sul. Esta frutífera vem sendo cultivada em várias regiões tropicais e subtropicais por todo o mundo. Dovyalis hebecarpa (Gardner) Warb., conhecida em Inglês como "Ceylon gooseberry", "kitembila", é originária do sul da Índia ou da ilha do Sri-Lanca (Mendes Ferrão, 1999). Segundo o mesmo autor, a propagação pode realizar-se por semente ou por via vegetativa (estaquia, enxertia ou alporquia).

O gênero Dovyalis pertence à Família Flacourtiaceae e compõe diversas espécies, entre as quais as espécies Dovyalis caffra e $D$. hebecarpa, que foram introduzidas na Flórida e, daí, um híbrido entre essas duas espécies foi trazido para o Brasil, pela Unesp de Jaboticabal (Donadio et al., 1998). Estes mesmos autores complementam, ainda, que Dovyalis sp, usualmente, é propagada por sementes, mas também por estacas e alporques. Porém, não mencionam qual metodologia, porcentagem de enraizamento, melhor época ou tratamentos a serem utilizados.

De acordo com Samson (1991), as plantas propagadas vegetativamente florescem mais rapidamente que as originadas por sementes, pois estas, normalmente, passam por um período juvenil que pode durar anos; neste período, as plantas podem apresentar vigor acentuado e características morfológicas típicas, como, por exemplo, espinhos. A juvenilidade não se distribui uniformemente em toda a árvore, persistindo por mais tempo no centro e base da copa; no entanto, nas zonas externas e superiores, entram mais rapidamente na fase reprodutiva. Segundo Castro e Silveira (2003), a propagação pelo método de alporquia apresenta vantagens em relação à estaquia, dentre as quais estão: o alto percentual de enraizamento, em muitos casos há independência de infra-estrutura (casa de vegetação com sistema de nebulização). A multiplicação assexuada pelo processo de alporquia ou mergulhia aérea tem registro em espécies como, por exemplo: lichia e caju (Almeida et al., 1991), umbu e gravioleira (Lederman et al., 1991), Ficus elastica (Hartman et al., 1997), uva (Pacheco et al., 1998) e pessegueiro (Castro e Silveira, 2003), sendo que, para a primeira, é o sistema de propagação mais utilizado comercialmente.

Diversos fatores estão relacionados com a maior ou menor facilidade de regeneração da planta, dentre os quais: espécie, posição dos ramos, época do ano, métodos de propagação (Simão, 1998). De acordo com Siqueira (1998), citado por Castro e Silveira (2003), o desenvolvimento das raízes pode ser estimulado por reguladores de crescimento e pelo anelamento do ramo que impede que carboidratos, hormônios e outras substâncias produzidas pelas folhas e gemas sejam translocados para outras partes da planta. Por sua vez, o xilema não é afetado, fornecendo água e elementos minerais ao ramo. Segundo os mesmos autores, a alporquia tradicional utiliza como substrato o esfagno, que é um produto desidratado, colhido em pântanos, proveniente de plantas do gênero Sphagnum. Por ser leve e poroso, apresenta grande capacidade de retenção de água ( 10 a 20 vezes o peso original), e seu conteúdo em minerais é baixo, e o pH varia de 3,5 a 4,0.

Este trabalho teve o objetivo de avaliar o potencial da alporquia na clonagem de Dovyalis sp., bem como o efeito do ácido indolbutírico, da posição do ramo na planta e da época do ano neste processo.

\section{MATERIAIS E MÉTODOS}

Segundo o Fortes et al. (1970), Jaboticabal está situada a $575 \mathrm{~m}$ de altitude a $21^{\circ} 16^{\prime}$ de latitude sul e $48^{\circ} 19^{\prime}$ de longitude oeste, distante 309 km da Capital paulista. O clima na classificação de Köeppen é do tipo Cwa e o solo é Latossolo Vermelho-Escuro e fase arenosa.

$\mathrm{O}$ experimento foi executado em uma única planta pertencente

\footnotetext{
1 (Trabalho 053/2004). Recebido: 07/05/2004. Aceito para publicação: 24/09/2004.

${ }^{2}$ Aluno do curso de pós graduação do Departamento de Produção Vegetal da FCAV/UNESP. Rod. Prof. Paulo Donato Castellani, s/n. cep 14.870-000. tel. 3209 2600. ramal 2668.

${ }^{3}$ Professor doutor do Departamento de Produção Vegetal da FCAV/UNESP. Rod. Prof. Paulo Donato Castellani, s/n. cep 14.870-000. tel. 3209 2600. ramal 2668.
} 
à coleção de frutas exóticas do Departamento de Produção Vegetal da FCAV/UNESP de Jaboticabal.

A planta, objeto de estudo, contava com cerca de $5,0 \mathrm{~m}$ de altura e 15 anos de idade, proveniente de propagação seminífera.

Para a realização dos alporques, foram utilizados ramos bem enfolhados e sadios, distribuídos por toda a planta. Os ramos escolhidos possuíam entre 1 e 1,5 cm de diâmetro, onde se realizou o anelamento, retirando-se um anel de casca de cerca de $1 \mathrm{~cm}$ de largura de todo o perímetro do ramo, a $50 \mathrm{~cm}$ da extremidade. Nesta região exposta, foram aplicadas as doses dos tratamentos com ácido indolbutírico (AIB), diluído em pasta de lanolina, nas concentrações $0 ; 1.000 ; 3.000 ; 5.000$ e 7.000 $\mathrm{mg} / \mathrm{kg}$. A aplicação contou com o auxílio de um pincel. Em seguida, o local foi recoberto com esfagno úmido e envolto com filme de polietileno (PVC) transparente, para a contenção do substrato e evitar a sua desidratação.

O experimento foi realizado em abril e outubro de 2003, respectivamente, outono e primavera. Efetuou-se a avaliação 60 dias após, com a separação dos ramos, da planta-matriz. Neste momento, os ramos foram separados conforme sua posição na planta: face da planta exposta ao norte e ao sul; posição superior e inferior da copa da planta. Da planta com 5,0 m de altura, considerou-se posição superior acima de $2,1 \mathrm{~m}$, e inferior, abaixo deste limite.

Os dados referentes à posição dos alporques na planta foram considerados como sub-parcelas. A avaliação da segunda época (primavera) não contabilizou o efeito da posição dos ramos na planta, devido à pequena disponibilidade de ramos distribuídos eqüitativamente por toda planta, impossibilitando, assim, obter-se as subparcelas. Avaliaram-se a percentagem de enraizamento, o número de raízes e o comprimento de raízes.

O delineamento experimental utilizado foi o inteiramente casualizado, com 5 tratamentos e 4 repetições, contendo 8 alporques por parcela, sendo consideradas como sub-parcelas as 2 faces da planta e 2 posições de ramos.

\section{RESULTADOS E DISCUSSÃO}

Os alporques realizados no outono apresentaram resultados superiores à primavera, para percentagem de enraizamento $(93,93$ e 82,,41 $\%$, respectivamente) e número médio de raízes $(10,26$ e 7,60, respectivamente) (Tabela 1). Estes dados não suportam a afirmação de Hartman et al. (1997) de que o período mais apropriado para a execução de alporques é a partir da primavera até o final do verão, quando as funções metabólicas da planta se encontram em plena atividade, fazendo com que haja grande síntese e armazenamento de carboidratos importantes na formação de raízes. Há que se ressaltar que, na ocasião da realização da alporquia, na primavera, a planta apresentava-se em frutificação, motivo pelo qual se poderia atribuir o menor enraizamento nesta época. Deve-se levar em consideração o fato de que alporques estão integralmente ligados à planta-matriz por todo o tempo de enraizamento, refletindo naquele o que ocorre nas diversas fases desta. A Figura 1 apresenta as condições meteorológicas do período que compreendeu o experimento. Observa-se que os trabalhos realizados no outono foram precedidos das chuvas de verão/outono, mantendo um balanço hídrico favorável; por sua vez, na primavera, a planta vinha de um estresse hídrico de, pelo menos, 4 meses, constituindo uma razão para o menor enraizamento.similar aos resultados do presente trabalho, Kersten et al. (1993) obtiveram os melhores resultados de enraizamento de estacas de ameixeira no outono e verão, que superaram o estaqueamento realizado na primavera.

Segundo Hartman e Loreti (1965) e Porlings e Sfakiotakis (1969), citados por Porlings e Therios (1976), a intensidade de luz e a fotossíntese variam com a estação do ano e podem contribuir para o enraizamento, mas há evidência de que outros fatores adicionais, tais como, nutrição, balanço hormonal e hídrico, estão envolvidos com a flutuação da resposta ao enraizamento.
TABELA 1 - Médias de percentagem de enraizamento, número e comprimento de raízes de alporques de Dovyalis sp., em relação à época do ano. FCAV/UNESP, Jaboticabal - SP, 2003.

\begin{tabular}{cccc}
\hline \hline Época & \% Enraizamento & $\begin{array}{c}\text { Número de } \\
\text { raízes }\end{array}$ & $\begin{array}{c}\text { Comprimento } \\
\text { de raízes }\end{array}$ \\
\hline Outono $^{*}$ & $93,93 \mathrm{a}$ & $10,26 \mathrm{a}$ & $1,46 \mathrm{~b}$ \\
Primavera $*$ & $82,41 \mathrm{~b}$ & $7,60 \mathrm{~b}$ & $2,17 \mathrm{a}$ \\
\hline $\mathbf{C v}(\%)$ & 14,07 & 15,05 & 6,58
\end{tabular}

* Médias seguidas pela mesma letra, na coluna, não diferem entre si, pelo teste de Tukey $(\mathrm{P}<0,05)$. Dados originais.

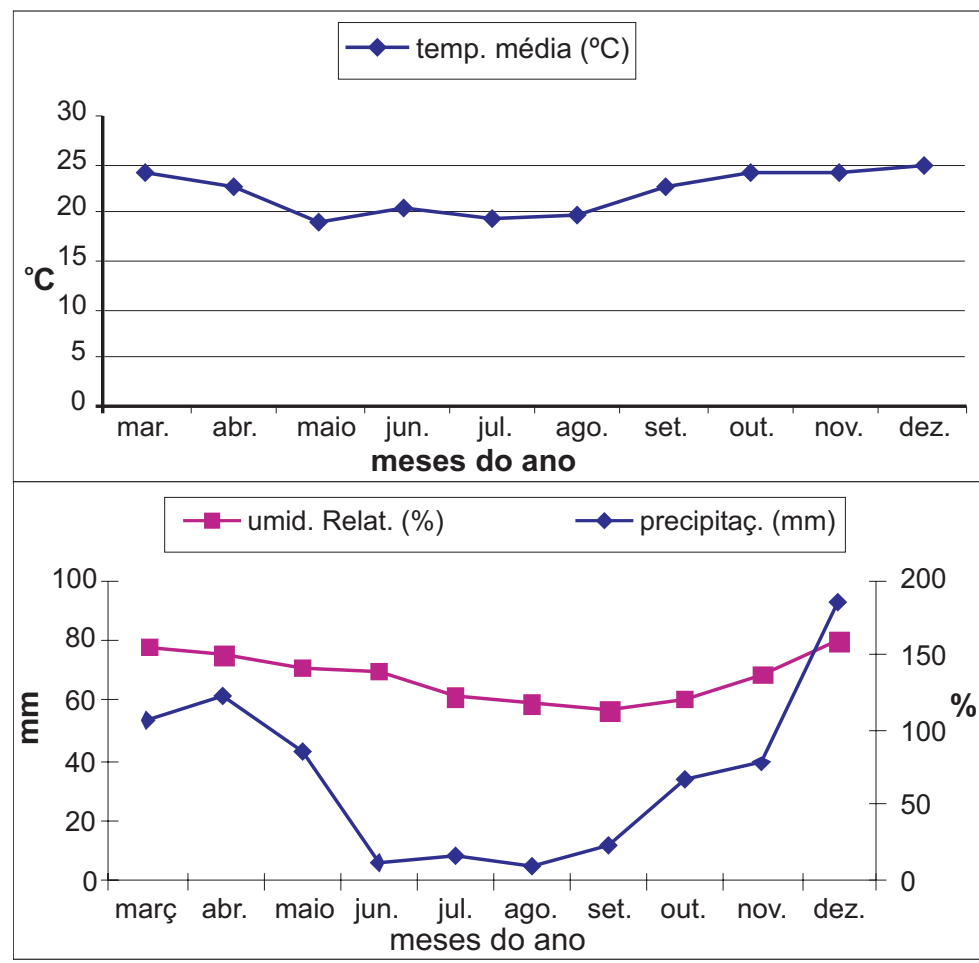

FIGURA 1 - Dados meteorológicos de Jaboticabal-SP, do período de abril a 14 de dezembro de 2003. Departamento de Ciências Exatas, FCAV/Unesp.

Na primavera, observou-se maior comprimento de raízes que no outono. Possivelmente, este fato ocorreu devido à temperatura ambiente que se eleva na primavera, ao passo que no outono a temperatura média decai, com a chegada do inverno (Tabela 1). Outra hipótese seria que, como houve um maior número de raízes no outono, isso implicaria maior competição entre elas por carboidratos, enquanto na primavera, com menor número de raízes, a partição de fotoassimilados seria menor.

No outono, os tratamentos com o regulador de crescimento não influenciaram na percentagem de alporques enraizados e no número médio de raízes por alporque. Com isso, pode-se supor que a rizogênese independe da aplicação de auxina exógena para esta espécie, na propagação pelo método de alporquia. Já, a dose de $7.000 \mathrm{mg} / \mathrm{kg}$ de AIB proporcionou maiores comprimentos de raízes $(1,78 \mathrm{~cm})$ (Tabela 2). Como o AIB é, segundo Hartman et al. (1997) e Wachowicz e Carvalho (2002), substância que está relacionada à divisão celular, provavelmente a relação direta entre doses e comprimento de raízes se explica pelo fato de haver uma antecipação da emissão de primórdios radiculares nos alporques tratados.

$\mathrm{Na}$ primavera, a dose de $3.000 \mathrm{mg} / \mathrm{kg}$ de AIB proporcionou maior percentagem de enraizamento $(93,30 \%)$, seguidos por $7.000 \mathrm{mg} / \mathrm{kg}$ $(87,5 \%), 5.000(78,12 \%)$ e $0 \mathrm{mg} / \mathrm{kg}(78,12 \%)$. O número e o comprimento médio de raízes não apresentaram diferenças significativas (Tabela 2). Alguns trabalhos com outras espécies apresentaram resultados em que o alporque responde positivamente ao regulador de crescimento, como Martins e Antunes (2000), que encontraram uma taxa de enraizamento para jambeiro-rosa (Syzygium jambos) de 55,00\%, sem uso de reguladores de crescimento, e de $97,5 \%$ com uso de $10.000 \mathrm{mg} / \mathrm{kg}$. 
TABELA 2 - Médias de percentagem de enraizamento, número e comprimento de raízes de alporques de Dovyalis sp. em relação à época do ano e doses de AIB (mg/Kg). FCAV/ UNESP, Jaboticabal - SP, 2003.

\begin{tabular}{cccc}
\hline \hline Época & \% Enraizamento * & $\begin{array}{c}\text { Número de } \\
\text { raízes * }\end{array}$ & $\begin{array}{c}\text { Comprimento } \\
\text { de raízes * }\end{array}$ \\
\hline Outono & $96,86 \mathrm{a}$ & $10,03 \mathrm{a}$ & $1,39 \mathrm{abc}$ \\
0 & $89,28 \mathrm{a}$ & $10,50 \mathrm{a}$ & $1,26 \mathrm{bc}$ \\
1.000 & $92,86 \mathrm{a}$ & $9,25 \mathrm{a}$ & $1,22 \mathrm{c}$ \\
3.000 & $100,00 \mathrm{a}$ & $12,12 \mathrm{a}$ & $1,69 \mathrm{ab}$ \\
5.000 & $91,67 \mathrm{a}$ & $9,38 \mathrm{a}$ & $1,74 \mathrm{a}$ \\
7.000 & 14,67 & 11,14 & 4,29 \\
$\mathbf{C v}(\%)$ & & & \\
\hline \hline Primavera & $78,12 \mathrm{ab}$ & $6,71 \mathrm{a}$ & $1,94 \mathrm{a}$ \\
0 & $75,00 \mathrm{~b}$ & $6,76 \mathrm{a}$ & $1,89 \mathrm{a}$ \\
1.000 & $93,30 \mathrm{a}$ & $7,33 \mathrm{a}$ & $1,95 \mathrm{a}$ \\
3.000 & $78,12 \mathrm{ab}$ & $9,11 \mathrm{a}$ & $2,86 \mathrm{a}$ \\
5.000 & $87,50 \mathrm{ab}$ & $8,11 \mathrm{a}$ & $2,21 \mathrm{a}$ \\
7.000 & 12,78 & 18,21 & 7,91 \\
\hline $\mathbf{C v}(\%)$ & &
\end{tabular}

* Médias seguidas pela mesma letra, na coluna, não diferem entre si, pelo teste de Tukey $(\mathrm{P}<0,05)$. Dados originais.

Segundo Porlingis e Therios (1976), características morfológicas de juvenilidade, como forma da folha, filotaxia, bem como características fisiológicas, como facilidade de enraizamento, habilidade para formar flores e retardamento na abscisão foliar, não são somente exibidos por plantas jovens, mas também por lançamento de ramos da parte inferior de árvores adultas de muitas espécies. Por outro lado, Heinicke (1963) afirma que diferentes posições do ramo na planta apresentariam respostas distintas ao enraizamento, pois a percentagem de luz solar que atinge o topo de uma árvore decresce até a base da copa, assim como a área foliar. Este motivo levaria a uma resposta diferente a produção de frutos e, também, de emissão radicular em ramos. No Brasil, em função das condições de clima tropical e alta radiação por todo ano, são raros os trabalhos considerando esta variável.

Contudo, não houve influência nos parâmetros avaliados da posição do alporque na planta (Tabela 3). Estes resultados concordam com Araújo et al. (1999), que observaram, em limeira ácida 'Tahiti', que a posição do ramo na planta não apresentou diferença significativa na emissão de raízes, mas o grau de lignificação das estacas foi marcadamente influente no enraizamento. No entanto, Porlingis e Therios (1976), em oliveira, observaram que estacas retiradas da parte inferior da planta apresentavam maior capacidade de enraizamento.

A pesar de a análise dos parâmetros avaliados na planta como um todo não evidenciar efeito da posição dos ramos na copa, este tratamento foi relacionado com a auxina no comprimento de raízes, no período do outono. Os resultados demonstraram que alporques da parte superior da copa responderam ao tratamento com AIB, apresentando raízes maiores que as da testemunha a partir da dose de $5.000 \mathrm{mg} / \mathrm{kg}$ (Tabela 4). Estes fatores foram estudados individualmente para citros e carambola, sendo que, no primeiro, a avaliação da posição do ramo na copa não influenciou no comprimento de raízes (Araújo et al., 1999); já para a segunda espécie, avaliou-se o efeito da auxina, onde a melhor resposta registrada também foi de $5.000 \mathrm{mg} / \mathrm{kg}$ de AIB (Natch, 1994). Por outro lado, Martins e Antunes (2000), com alporques de jambeiro-rosa, concluíram que os tratamentos com AIB não influenciaram no comprimento de raízes desta espécie, demonstrando que há efeito da espécie, do regulador de crescimento e da posição do ramo na planta na emissão e qualidade das raízes formadas.

TABELA 3 - Efeito das posições superior e inferior, face norte ou sul da copa de Dovyalis sp. na percentagem de enraizamento, número e comprimento de raízes por alporque, no outono. FCAV/UNESP, Jaboticabal - SP, 2003.

\begin{tabular}{|c|c|c|c|c|c|c|c|}
\hline & $\% \mathrm{E}^{*}$ & NR * & CR * & & $\% \mathrm{E}^{*}$ & NR * & CR * \\
\hline Parte superior & $80,12 \mathrm{a}$ & $3,20 \mathrm{a}$ & $1,59 \mathrm{a}$ & Face norte & $83,88 \mathrm{a}$ & $3,33 \mathrm{a}$ & $1,53 \mathrm{a}$ \\
\hline Cv (\%) & 20,71 & 19,11 & 4,87 & & 18,21 & 18,53 & 7,28 \\
\hline
\end{tabular}

* Médias seguidas pela mesma letra não diferem entre si, pelo teste de Tukey $(\mathrm{P}<0,05) . \% \mathrm{E}$ - percentagem de alporques enraizados; NR - número de raízes por alporques; $\mathrm{CR}$ - comprimento de raízes. Dados originais.

TABELA 4 - Médias de percentagem de enraizamento, número e comprimento de raízes de Dovyalis sp. por alporques em relação à época e partes superior e inferior, faces norte e sul, da planta. FCAV/UNESP, Jaboticabal - SP, 2003.

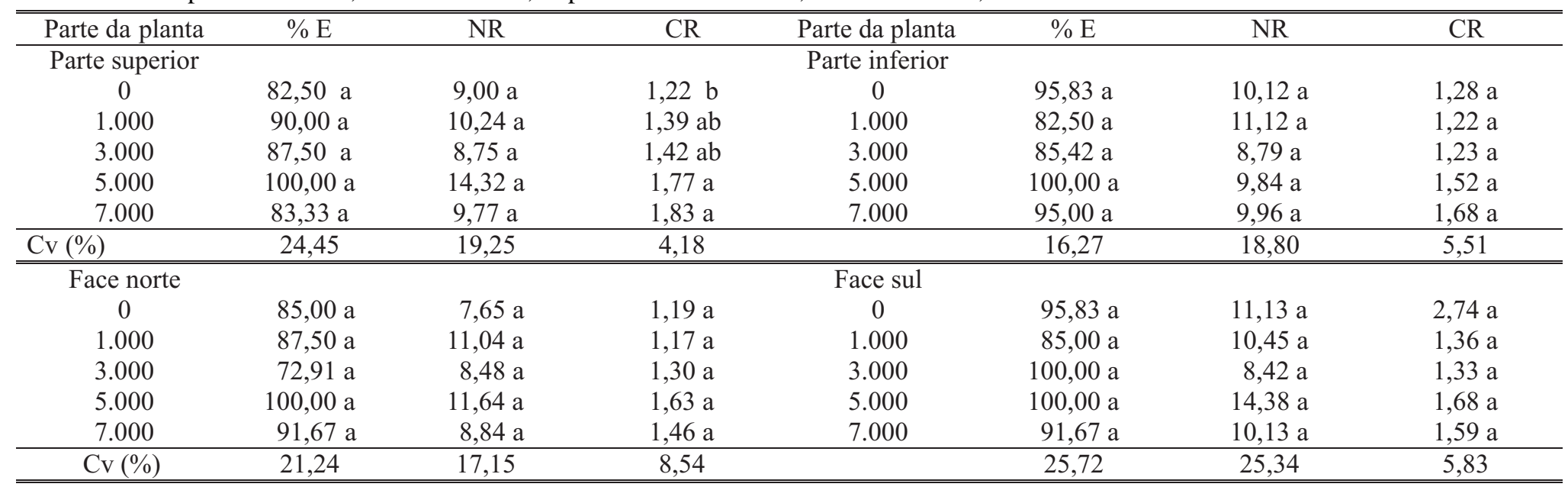

* Médias seguidas pela mesma letra, na coluna, não diferem entre si, pelo teste de Tukey $(\mathrm{P}<0,05)$.

\section{CONCLUSÕES}

1) A época de realização de alporquia influenciou nos resultados, sendo recomendado o outono, entre as épocas estudadas, para obtenção de melhor porcentagem de enraizamento.

2) É possível a propagação de Dovyalis sp. pelo método de alporquia sem o uso de reguladores de crescimento no outono, em ramos de qualquer posição da copa.

3) Na primavera, a aplicação de $3.000 \mathrm{mg} / \mathrm{kg}$ de AIB induziu a uma maior percentagem de alporques enraizados.

4) Os resultados foram altamente satisfatórios, indicando que a alporquia é uma técnica eficiente para produção de mudas de Dovyalis sp. 


\section{REFERÊNCIAS}

ALMEIDA, F. C. G.; ALMEIDA, F. A. G; CARVALHO, P. R.; LEÃO, R.A. O.; NOGUEIRA FILHO, G. C.; VIEIRAA. V. A. Efeito da quebra da dominância apical no sistema radicular no pegamento em campo de alporques de cajueiro. Revista Brasileira de Fruticultura, Cruz das Almas, v. 13, n. 1, p. 251-255, 1991.

ARAÚJO, P. S. R.; MOURÃOFILHO, F. A. A.; SILVA, J.A. F.; BARBANO, M. T. Enraizamento de estacas de limeira ácida 'Tahiti' coletadas em diferentes posições na árvore. Scientia Agrícola, Piracicaba, v. 56, n. 2, p. 357-361, 1999.

CASTRO, L. A. S.; SILVEIRA, C. A. P. Propagação vegetativa do pessegueiro por alporquia. Revista Brasileira de Fruticultura, Jaboticabal, v. 25, n. 2, p. 368 - 370, 2003.

DONADIO, L. C. Introdução e avaliação de novas frutíferas de clima tropical e subtropical. Revista Brasileira de Fruticultura, Cruz das Almas, v. 13, n. 3, p. 49-54, 1991.

DONADIO, L. C.; NACHITIGAL, J. C.; SACRAMENTO, L. K. Frutas exóticas. Jaboticabal: FUNEP, 1998, 279p.

FORTES, A. B.; PRUNES, L. M.; CASTRO, M. I. B.; PIVA, S. R. (Colab.). Dicionário geográfico brasileiro: GLOBO, 1970.559p.

HARTMAN, H. T.; KESTER, D. E.; DAVIES Jr., F. T.; GENEVE, R. L. Plant propagation: principles and practices. 6 . ed. New Jersey: Prentice Hall, 1997.770p.

HEINICKE, D. R. The micro-climate of fruit tree. II. Foliage and light distribution patterns in apple trees. Proceedings of the American Society for Horticultural Science, Maryland, v. 8, n. 1, p. 1-11, 1963.
KERSTEN, E.; LUCCHESI, A. A.; GUTIERREZ, L. E. Efeito do ácido indolbutírico no enraizamento de estacas de ramos de plantas de ameixeira (Prunus salicina Lindl.). Scientia Agrícola, Piracicaba, v. 50, n. 1, p. 19-26, 1993.

LEDERMAN, I. E.; BEZERRA, J. E. F.; ASCHOFF, M. N. A.; OLIVEIRA, E. N. M.; ROSA, J. M. G. Propagação vegetativa do umbuzeiro (Spondias tuberosa Arr. Cam.) e da gravioleira (Annona muricata L.) através da alporquia. Revista Brasileira de Fruticultura, Cruz das Almas, v. 13, n. 1, p. 55-58, 1991.

MARTINS, A. B. G.; ANTUNES, E. L. Propagação do jambeiro-rosa (Sizigyum jambos L. Alston.) pelo processo de alporquia. Revista Brasileira de Fruticultura, Jaboticabal, v. 22, n. 2, p. 205-207, 2000.

MENDES-FERRÃO, J. E. Fruticultura tropical: espécies com frutos comestíveis. Lisboa: IICT, 1999, 621p.

NATCH, J. C. Studies in vegetative propagation of carambola (Averrhoa carambola Linn.) by air-layering. Horticultural Journal, Calcutá, v. 7, n. 1, p. 63-65, 1994.

PACHECO, A. L.; CASTRO, P. R. C.; APPEZZATO, G. Aspectos anatômicos de raízes de videira muscadínia (Vitis rotundifolia Michx.) propagadas através da alporquia. Scientia Agrícola, Piracicaba, v. 55, n. 2, p. 210-217, 1998.

PORLINGS, I. C.; THERIOS, J. Rooting response of juvenile and adult leafy olive cuttings to various factors. Journal of Horticultural Science, London, v. 51, n. 1, p. 31-39, 1976.

SAMSON, J. A. Fruticultura tropical. Balderas: LIMUSA, 1991, 369p. SIMÃO, S. Tratado de fruticultura. Piracicaba: Fealq, 1998. 700p.

WACHOWICZ, C. M.; CARVALHO, R. I. N. (Org.) Fisiologia vegetal e pós-colheita. Curitiba: CHAMPAGNAT, 2002, 424p. 